\title{
ALPHA-STAT ACID-BASE REGULATION DURING CARDIOPULMONARY BYPASS IMPROVES NEUROPSYCHOLOGIC OUTCOME IN PATIENTS UNDERGOING CORONARY ARTERY BYPASS GRAFTING
}

\author{
R. L. Patel, MD, FRCS (CTh) ${ }^{\mathrm{a} *}$ \\ M. R. Turtle, BSc ${ }^{a}$ \\ D. J. Chambers, PhD \\ D. N. James, $\mathrm{MSc}^{\mathrm{b}}$ \\ S. Newman, DPhil ${ }^{\mathrm{b}}$ \\ G. E. Venn, MS, FRCS ${ }^{\mathrm{a}}$
}

Neuropsychologic impairment in patients undergoing cardiopulmonary bypass may be associated with cerebral blood flow changes arising from different management protocols for carbon dioxide tension during bypass. Seventy patients having coronary artery bypass grafting were randomized to either pH-stat or alpha-stat acid-base management during cardiopulmonary bypass with a membrane oxygenator. In each patient, cerebral blood flow (xenon 133 clearance), middle cerebral artery blood flow velocity (transcranial Doppler sonography), and cerebral oxygen metabolism (cerebral metabolic rate and cerebral extraction ratio) were measured during four phases of the operation: before bypass, during bypass (at hypothermia and at normothermia), and after bypass. A battery of neuropsychologic tests were also conducted before and 6 weeks after the operation. During hypothermic $\left(28^{\circ} \mathrm{C}\right.$ ) bypass, cerebral blood flow was significantly ( $p<$ $0.001)$ greater in the pH-stat group $\left(41 \mathrm{ml} \cdot 100 \mathrm{gm}^{-1} \cdot \mathrm{min}^{-1} ; 95 \%\right.$ confidence interval 39 to $43 \mathrm{ml} \cdot 100 \mathrm{gm}^{-1} \cdot \mathrm{min}^{-1}$ ) than in the alpha-stat group $\left(24 \mathrm{ml} \cdot 100 \mathrm{gm}^{-1} \cdot \mathrm{min}^{-1}\right.$; confidence interval 22 to $26 \mathrm{ml} \cdot 100$ $\mathrm{gm}^{-1} \cdot \mathrm{min}^{-1}$ ) at constant pressure and flow. Arterial carbon dioxide tensions were $41 \mathrm{~mm} \mathrm{Hg}(40$ to $41 \mathrm{~mm} \mathrm{Hg}$ ) and $26 \mathrm{~mm} \mathrm{Hg} \mathrm{(25} \mathrm{to} 27 \mathrm{~mm}$ Hg), respectively; pH was 7.36 (7.34 to 7.38 ) and 7.53 (7.51 to 7.55 ), respectively. Middle cerebral artery flow velocity was significantly $(p<$ $0.05)$ reduced in the alpha-stat group to $87 \%(77 \%$ to $96 \%)$ of the prebypass value, whereas it was significantly $(p<0.05)$ increased $(152 \% ; 141 \%$ to $162 \%$ ) in the pH-stat group. Cerebral extraction ratio for oxygen demonstrated relative cerebral hyperemia during hypothermic $\left(28^{\circ} \mathrm{C}\right)$ bypass in both the pH-stat and alpha-stat groups $(0.12[0.11$ to 0.14$]$ and $0.25[0.22$ to 0.28 , respectively); however, hyperemia was significantly more pronounced in the pH-stat group, indicating greater disruption in cerebral autoregulation. Neuropsychologic impairment criteria of deterioration in results of three or more tests revealed that a significantly (Fisher's exact test, $p=0.02$ ) higher proportion of patients in the $\mathrm{pH}$-stat group fared poorly than in the alpha-stat group at 6 weeks $(17 / 35,48.6 \%[32 \%$ to $65.1 \%]$, and $7 / 35,20 \%$ [6.7\% to $33.2 .2 \%]$, respectively). In conclusion, patients receiving alpha-stat management had less disruption of cerebral autoregulation during cardiopulmonary bypass, accompanied by a reduced incidence of postoperative cerebral dysfunction. (J Thorac Cardiovasc Surg 1996;111:1267-79)
From the Departments of Cardiothoracic Surgery and Cardiac Surgical Research, The Rayne Institute, St. Thomas' Hospital, ${ }^{a}$ London, and Academic Psychiatry, University College and Middlesex Hospital School of Medicine, Middlesex Hospital, ${ }^{\mathrm{b}}$ London, United Kingdom.

This work was supported by the Sir Jules Thorn Charitable Trust and the Research Endowments Trust of St. Thomas' Hospital.

Received for publication August 14, 1995; revisions requested Sept. 25, 1995; revisions received Oct. 25, 1995; accepted for publication Oct. 27, 1995.
Address for reprints: D. J. Chambers, PhD, Research Director, Cardiac Surgical Research, The Rayne Institute, St. Thomas' Hospital, London SE1 7EH, United Kingdom.

*Present address: Department of Cardiothoracic Surgery, Walsgrave Hospital, Coventry, CV2 2DX, United Kingdom.

Copyright (C) 1996 by Mosby-Year Book, Inc.

$0022-5223 / 96 \$ 5.00+0 \quad \mathbf{1 2 / 1 / 7 0 3 2 5}$ 
$\mathrm{M}$ any studies have reported both short-term and long-term changes in neuropsychologic performance after coronary artery bypass grafting (CABG).$^{1-7}$ The prevalence of neuropsychologic morbidity in these studies varies from $12 \%$ to $79 \%$, often reflecting differing assessment protocols. This dysfunction is usually mild and typically manifested by difficulties in attention, concentration, and memory. The duration is less well defined, but dysfunction may last up to 1 year after the operation ${ }^{8}$ and may become unmasked, after recovery, many years later ${ }^{9}$. Although some of the variation in prevalence may be attributed to differences in the neuropsychologic assessment, it has become apparent that operative technique may affect neuropsychologic outcome. ${ }^{10,11}$

Substantial alterations in cerebral blood flow (CBF) are known to occur during cardiopulmonary bypass (CPB). ${ }^{12-14}$ Although investigators have speculated that these changes may be responsible for both minor and major cerebral damage after $\mathrm{CPB}$, definitive proof is lacking. More recently, these changes in CBF have been seen to be intimately related to arterial carbon dioxide tension $\left(\mathrm{PaCO}_{2}\right)$ maintained during hypothermic CPB. ${ }^{15,16}$ One of the main instigators of neuropsychologic impairment after CABG is thought to be microembolism, which is a widely recognized phenomenon that occurs during $\mathrm{CPB} .{ }^{17-20}$ Alterations in $\mathrm{CBF}$ during $\mathrm{CPB}$, induced by the altered acid-base management of the patient, may influence the microembolic delivery to the brain and, in turn, neuropsychologic outcome. Although Bashein and colleagues ${ }^{21}$ have addressed the issue of different acid-base regulation both in patients having $\mathrm{CABG}$ (closed heart surgery) and in those having valve operations (open heart surgery) and have shown no difference in the overall neuropsychologic score between the groups, the hypothesis has not been tested in a relatively large trial of patients having $\mathrm{CABG}$ alone.

The current study addresses the issue of neuropsychologic outcome after randomized allocation of patients having $\mathrm{CABG}$ to either alpha-stat or $\mathrm{pH}$ stat acid-base regulation during CPB. Neuropsychologic outcome was evaluated by intraoperative measurement of CBF, velocity of blood flow in the middle cerebral artery, and cerebral metabolism.

\section{Methods and patients}

Patients. Ethical approval for this study was obtained from the West Lambeth Health Authority ethical committee at St. Thomas' Hospital; written informed consent was obtained from each patient. Seventy patients undergoing elective $\mathrm{CABG}$, under the care of one surgical team, were studied. The patients were randomized to undergo CPB managed by either alpha-stat or pH-stat acid-base protocols (35 patients per group) by means of computergenerated random-number assignment. Patients with insulin-dependent diabetes and those with preexisting cerebrovascular disease were excluded from the study. Preexisting cerebrovascular disease was defined as a cerebrovascular event in the near or distant past (stroke, transient ischemic attack, and inclusive of patients with epilepsy and carotid bruit); however, none of the patients had invasive or noninvasive investigations of extracranial or intracranial vascular abnormalities. All patients underwent intraoperative measurement of $\mathrm{CBF}$, velocity of blood flow in the middle cerebral artery, cerebral metabolic rate for oxygen $\left(\mathrm{CMRO}_{2}\right)$, and assessment of neurologic and neuropsychologic changes after $\mathrm{CABG}$.

Study design. Our original study size assessment, assuming a typical "placebo" incidence of impairment at 8 weeks to be $35 \%$ and the intervention group to demonstrate a reduction to $15 \%$, indicated a patient group size of 74 , which would have necessitated a long and expensive study. Consequently, we analyzed individual neuropsychologic test results in terms of difference scores (i.e., the difference between the test and the preoperative "control" test) from a previous study by a coworker. We used the following formula to obtain sample sizes for the various tests: $g=\mu 1-\mu 2 / d$ (where $g=$ effect size, $\mu 1$ and $\mu 2=$ the respective group means, $d=$ standard deviation, and the desired power of the study is $80 \%$ ). According to this formula, sample sizes for the Rey Auditory Verbal Learning test, the Symbol Digit test, the Nonverbal Memory test $\mathrm{A}$, and the Nonverbal Memory test $\mathrm{B}$ were 28,33 , 48 , and 34 patients per group, respectively. We assumed that the difference between our two groups would be at least as great and that randomization of 35 patients per group would provide sufficient sample size for our study.

Hemodynamic measurements. Mean arterial pressure was transcribed every 30 seconds onto a microcomputer throughout CPB. Each 30-second period was considered as a separate epoch. From the individual blood pressure recordings for each epoch, an integral of the arterial pressure less than $50 \mathrm{~mm} \mathrm{Hg}$ was calculated to give the hypotension index, TM $<50$ (as defined by Stockard, Bickford, and Schauble ${ }^{22}$ as the product of blood pressure less than $50 \mathrm{~mm} \mathrm{Hg}$ and duration in minutes that this pressure existed). Mean arterial pressure was recorded during the four phases of the operation when CBF and flow velocity in the middle cerebral artery were measured: before $\mathrm{CPB}$, during hypothermic CPB $\left(28^{\circ} \mathrm{C}\right)$, during normothermic $\mathrm{CPB}\left(37^{\circ} \mathrm{C}\right)$, and after $\mathrm{CPB}$. Nasopharyngeal temperature was also measured, because it is an important covariant for $\mathrm{CBF}$, flow velocity in the middle cerebral artery, and acid-base management.

CBF. CBF was measured by xenon $133\left({ }^{133} \mathrm{Xe}\right)$ clearance technique with a two-detector system (Novocerebrograph 10a, Nova Diagnostic Systems, Bagsvaerd, Denmark). Prebypass and postbypass measurements of $\mathrm{CBF}$ were obtained after intracarotid injection of $2 \mathrm{mCi}$ of ${ }^{133} \mathrm{Xe}$ dissolved in sterile saline solution (Amersham International, Ltd., Bucks, United Kingdom) and during $\mathrm{CPB}$ by injection of 10 to $15 \mathrm{mCi}$ of ${ }^{133} \mathrm{Xe}$ into the arterial 
limb of the perfusion circuit. CBF was recorded as mean hemispheric values $\left(\mathrm{ml} \cdot 100 \mathrm{gm}^{-1} \cdot \mathrm{min}^{-1}\right)$ measured during 15 -minute clearance of the ${ }^{133} \mathrm{Xe}$ during the four phases of the operation: before bypass, during hypothermic bypass $\left(28^{\circ} \mathrm{C}\right)$, during normothermic bypass $\left(37^{\circ} \mathrm{C}\right)$, and after bypass. The xenon-tissue partition coefficients were corrected for differences in hematocrit value and temperature. ${ }^{23}$ Prebypass CBF was measured after sternotomy and before CPB; postbypass CBF was measured once hemodynamic stability was attained and before the chest was closed. As far as possible, the prebypass and postbypass CBFs were measured at reasonably equivalent blood pressures and at similar times during the operative procedure, although the precise timing of CBF measurements varied slightly among patients. During $C P B$ the mean arterial pressure was maintained at $50 \mathrm{~mm} \mathrm{Hg}$. The pump flow at hypothermic $\left(28^{\circ} \mathrm{C}\right) \mathrm{CPB}$ was maintained at $1.75 \mathrm{~L} \cdot \mathrm{min}^{-1} \cdot \mathrm{m}^{-2}$; during normothermic $\left(37^{\circ} \mathrm{C}\right) \mathrm{CPB}$ it was maintained at $2.4 \mathrm{~L} \cdot \min ^{-1} \cdot \mathrm{m}^{-2}$. Nasopharyngeal temperatures were recorded at the same time as the CBF measurements.

Doppler flow velocity in the middle cerebral artery. A 2 $\mathrm{MHz}$ pulsed Doppler ultrasonic velocimeter (EME TCD2-64, Eden Medizinische Elektronik $\mathrm{GmbH}$, Uberlingen, Germany) was used to measure velocity of blood flow in the middle cerebral artery. The patient was positioned on the operating table and the ultrasonic transducer was placed on the right side of the head just above the zygomatic process. The orientation and the depth of the Doppler signals were adjusted to obtain the best possible signal strength. The position of the probe was then fixed in two planes with a specially designed holder; care was taken not to dislodge the probe throughout the surgical procedure. The instrument and details of examination procedures have been previously described. ${ }^{24}$

For each patient, blood flow velocity in the middle cerebral artery was recorded every minute for 15 minutes during the four phases of the operation: before bypass, during hypothermic $\left(28^{\circ} \mathrm{C}\right)$ bypass, during normothermic $\left(37^{\circ} \mathrm{C}\right)$ bypass, and after bypass. As far as possible, the prebypass and postbypass blood flow velocities in the middle cerebral artery were measured at reasonably equivalent blood pressures and at similar times during the operative procedure. During CPB the mean arterial pressure was maintained at $50 \mathrm{~mm} \mathrm{Hg}$, with the pump flow at hypothermic $\left(28^{\circ} \mathrm{C}\right) \mathrm{CPB}$ maintained at $1.75 \mathrm{~L} \cdot \mathrm{min}^{-1}$. $\mathrm{m}^{-2}$ and during normothermic $\left(37^{\circ} \mathrm{C}\right) \mathrm{CPB}$ at $2.4 \mathrm{~L}$. $\min ^{-1} \cdot \mathrm{m}^{-2}$. Nasopharyngeal temperatures were recorded at each phase of the operation when the blood flow velocity in the middle cerebral artery was measured.

The fundamental limitation of transcranial Doppler sonography is the individual variance of the cross-sectional diameter of the middle cerebral artery, where a wide range of normal results are observed. ${ }^{24,25}$ This limitation was overcome by normalizing the prebypass values to $100 \%$; consequently, each patient acts as his or her own control, and data are reported as changes in velocity of blood flow in the middle cerebral artery.

Cerebral metabolism. A $15 \mathrm{~cm}$ long $16 \mathrm{~F}$ catheter was introduced by a retrograde percutaneous method into the right jugular bulb. Postoperative skull roentgenograms confirmed the appropriate location of the jugular bulb catheter in all patients. Effluent cerebral venous blood and arterial blood were sampled simultaneously, and oxygen content was measured (Haemoximeter OSM 3, Radiometer A/S, Copenhagen, Denmark) for assessment of cerebral oxygen metabolism. These values were used to calculate $\mathrm{CMRO}_{2}$ and cerebral extraction ratio for oxygen $\left(\mathrm{CERO}_{2}\right)$

The $\mathrm{CMRO}_{2}$ was calculated as a product of $\mathrm{CBF}$ and cerebral arteriovenous oxygen content difference:

$$
\mathrm{CMRO}_{2}=\mathrm{CBF} \times \mathrm{CAVO}^{2}
$$

where $\mathrm{CAVO}_{2}$ is the cerebral arteriovenous oxygen content difference.

The $\mathrm{CERO}_{2}$ was calculated as a ratio of cerebral arteriovenous content difference and arterial oxygen content:

$$
\mathrm{CERO}_{2}=\mathrm{CAVO}_{2} / \mathrm{CAO}_{2}
$$

where $\mathrm{CAO}_{2}$ is the cerebral arterial oxygen content

Neurologic and neuropsychologic assessment. Detailed neurologic examination, to a standardized protocol, was carried out before the operation and 6 weeks after the operation. The observations were categorized and reported only as focal neurologic deficit related to CPB.

Neuropsychologic assessments were also conducted before the operation and were repeated 6 weeks after the operation by means of a well tried and tested series of ten assessments. All the patients completed all the ten tests; the mean assessment time after the operation was $42 \pm 4$ (standard deviation) days. The investigators were blinded as to group assignment while they were conducting the neuropsychologic tests. The tests fell into four categories: (1) memory, (2) attention and concentration, (3) perceptuomotor ability, and (4) visuo-spatial ability. Further details of the specific tests used can be found in the appendix.

Calculation of neuropsychologic deficit. The calculation of a neuropsychologic deficit in this study is based on that described by Newman. ${ }^{5}$ In brief, this involved determining a standard deviation of each test during the preoperative assessment for the whole group and calculating the change (difference score) for each individual from the preoperative to the postoperative assessment. A deterioration in performance at 6 weeks equivalent to, or greater than, one standard deviation in any patient when compared with his or her own preoperative score was considered to have shown a deficit in that test. A patient was considered to have a neuropsychologic deficit if deficits were demonstrated in two or more of the neuropsychologic tests. This essentially allows the patient a "leeway" of one test failure in the postoperative assessment.

CABG. Anesthesia and surgery were standardized for the two groups. Benzodiazepine (midazolam 2 to $4 \mathrm{mg}$ ) and papaveretum (10 to $20 \mathrm{mg}$ ) were used for premedication. Anesthesia was induced with thiopental (2 to 4 $\mathrm{mg} / \mathrm{kg}$ ) and vecuronium and maintained with intravenous fentanyl (10 to $20 \mu \mathrm{g} / \mathrm{kg}$ ). Volatile inhalation anesthetics were avoided. A nonpulsatile CPB pump with a membrane oxygenator (Harvey 1600, Bard Cardiopulmonary Division, C.R. Bard, Inc., Santa Ana, Calif.) and a $40 \mu \mathrm{m}$ arterial line filter (Pall Biomedical Products, Glen Cove, 
Table I. Comparison of demographic data, anxiety state, depression scores and intelligence quotient (IQ) of patient groups

\begin{tabular}{|c|c|c|c|c|c|}
\hline & \multicolumn{2}{|c|}{ Alpha-stat } & \multicolumn{2}{|c|}{$p H$-stat } & \multirow{2}{*}{$\begin{array}{c}t \text { Test } \\
\text { P Value }\end{array}$} \\
\hline & Mean & $95 \% \mathrm{CI}$ & Mean & $95 \% C I$ & \\
\hline Age (yr) & 56.9 & $54.9-58.9$ & 57.6 & $54.9-60.2$ & 0.69 \\
\hline Female/male ratio & $1 / 34$ & & $3 / 32$ & & 0.61 \\
\hline Beck depression score & 8 & $6-10$ & 10 & $8-11$ & 0.113 \\
\hline Anxiety state score & 36 & $33-40$ & 38 & $35-41$ & 0.543 \\
\hline Verbal IQ & 112 & $105-118$ & 111 & $104-119$ & 0.94 \\
\hline Nonverbal IQ & 146 & $141-150$ & 147 & $141-154$ & 0.62 \\
\hline Aortic crossclamp time (min) & 39.7 & $36-43.5$ & 40.3 & $35.2-45.3$ & 0.86 \\
\hline CPB time $(\min )^{x}$ & 75.1 & $69.2-81.0$ & 83.4 & $70.1-96.7$ & 0.25 \\
\hline
\end{tabular}

N.Y.) was used. The circuit was primed with compound sodium lactate solution (Hartmann's solution: Baxter Healthcare UK, Division of Baxter Healthcare Corp., Deerfield, Ill.). A systemic pump flow of $2.4 \mathrm{~L} \cdot \mathrm{min}^{-1} \cdot \mathrm{m}^{-2}$ was maintained at normothermia and reduced to $1.75 \mathrm{~L} \cdot \mathrm{min}^{-1}$ $\cdot \mathrm{m}^{-2}$ during hypothermia. The operation was performed with core cooling to $28^{\circ} \mathrm{C}$ (nasopharyngeal temperature). Myocardial protection was achieved with St. Thomas' Hospital cardioplegic solution No 1. Mean arterial pressure during bypass was maintained as close to $50 \mathrm{~mm} \mathrm{Hg}$ as possible by an $\alpha$-adrenergic agonist (metaraminol) or antagonist (phentolamine) in both groups.

Acid-base management during the operation. Endtidal carbon dioxide was analyzed with an online capnograph (model 47210A, Hewlett-Packard Company, Andover, Mass.), and the minute volume of the respirator was adjusted to maintain the $\mathrm{PaCO}_{2}$ at $40 \mathrm{~mm} \mathrm{Hg}$ before and after bypass. During bypass, continuous arterial blood monitoring (Cardiomet 4000; Shiley UK, Division of Mallinckrodt Medical TPI, Inc., Irvine, Calif.) allowed precise control of acid-base status in both the $\mathrm{pH}$-stat and alpha-stat groups. Any necessary corrections in the acidbase status during CPB were made immediately by the perfusionist. $\mathrm{PaCO}_{2}$ during bypass was regulated by adjusting oxygenator total gas flow, with additional carbon dioxide given as necessary. During bypass, arterial $\mathrm{pH}$ and $\mathrm{Paco}_{2}$ in patients with $\mathrm{pH}$-stat management were maintained at 7.4 and $40 \mathrm{~mm} \mathrm{Hg}$, respectively, corrected to the core temperature of the patient; in the alpha-stat group these values were maintained uncorrected to their core temperature. Arterial $\mathrm{pH}$ and $\mathrm{PaCO}_{2}$ were recorded onto a computer every minute during bypass. Oxygen saturation was monitored continuously by means of pulse oximetry (model B IOX 3700E; Ohmeda, Liberty Corner, N.J.) before bypass, after termination of bypass, and during recovery in the intensive care unit. Full acid-base and arterial blood gas profiles were obtained during CBF measurements before bypass, after bypass, and on return to the intensive care unit. $\mathrm{Paco}_{2}$ was monitored off bypass by means of intermittent arterial blood sampling and analysis with a conventional blood gas analyzer (ABL4, Radiometer). Subsequent sampling was undertaken according to the progress of the patient and pulse oximetry recordings.

Statistics. Data are expressed as mean and 95\% confidence intervals $(95 \% \mathrm{CI})$. Student's $t$ test (two-sided) was used for intergroup comparisons and Fisher's exact test for dichotomous data. Data were analyzed with StatView SE + Graphics statistics software package on an Apple Macintosh LC computer (Apple Computer, Cupertino, Calif.).

\section{Results}

Patient characteristics. A total of 70 patients were randomized into either alpha-stat management or $\mathrm{pH}$-stat management. There were no significant differences between groups concerning age, sex, anxiety state, depressed mood, verbal or nonverbal intelligence quotient estimates, aortic crossclamp time, or bypass time (Table I). None of the patients in either group had focal neurologic impairment after the operation.

Twenty patients in the alpha-stat group were extubated in the operating theater and 25 patients in the $\mathrm{pH}$-stat group. The mean extubation time in the remaining patients was 2 hours $(95 \% \mathrm{CI}, 1$ to 4 hours) in the alpha-stat group and 2 hours $(95 \% \mathrm{CI}$, 1 to 3 hours) in the $\mathrm{pH}$-stat group. Low cardiac output necessitating inotropic support developed in four patients in each group; this support was provided by epinephrine or norepinephrine, with or without dobutamine. In addition, one patient in the alpha-stat group required an intraaortic balloon assist device. None of the patients had cardiac arrest in the postoperative period. For the first 24 hours after the operation all the patients received an infusion of morphine for analgesia and an intravenous infusion of glycerine trinitrate to aid peripheral vasodilation. Three patients in the alpha-stat group and two in the $\mathrm{pH}$-stat group required more than 24 hours' stay in the intensive care unit. Four patients in the alpha-stat and three patients in the $\mathrm{pH}$-stat group required hospitalization for more than 10 days. Two patients died during the study period, one on the operating table and the other 4 weeks after the operation before completion of postoperative 


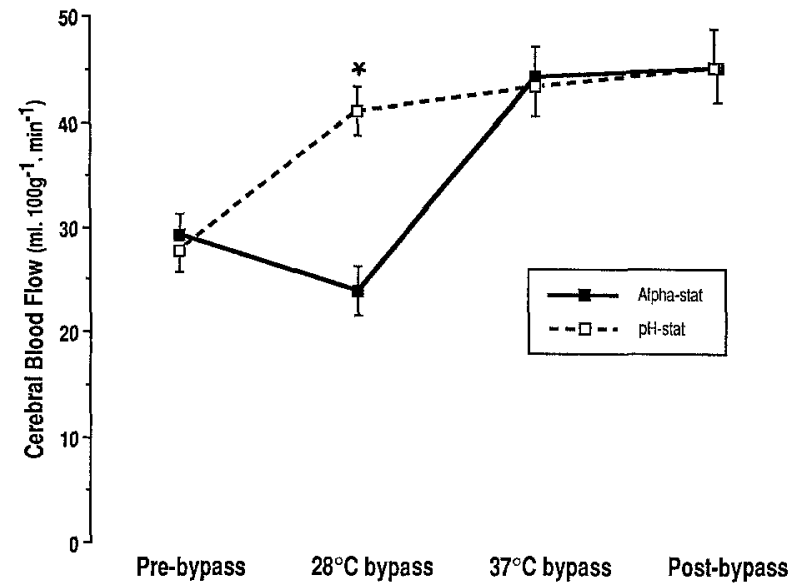

Fig. 1. Changes in $\mathrm{CBF}$ in the alpha-stat and pH-stat groups at the four phases of the operation. Values are mean $\pm 95 \%$ CI. Asterisk, $p<0.05$ when compared with results in the alpha-stat group.

neuropsychologic testing. Their data have not been presented in the results or analysis. Extra patients were recruited to the study to bring the sample size to 35 patients in each group. Mean hospital stay in the alpha-stat group was 7 days (95\% CI, 6 to 8 days) and in the pH-stat group it was 7 days (95\% CI, 6 to 8 days). There was no statistical difference in extubation time $(p=0.65$ ) or hospital stay $(p=$ 0.97). Complete preoperative and postoperative neuropsychologic data were available for analysis for all 70 patients. None of the patients had a stroke, which could have made the postoperative assessment difficult.

Hemodynamic measurements. Mean arterial pressure was similar between the two groups of patients at each of the four phases of the operation when indices of cerebral perfusion and metabolism were determined. During the prebypass phase, mean arterial pressure was around $70 \mathrm{~mm} \mathrm{Hg}$; as described in the Methods section, mean arterial pressure was reduced and maintained as close to 50 $\mathrm{mm} \mathrm{Hg}$ as possible during CPB (range was 49 to 55 $\mathrm{mm} \mathrm{Hg}$ for all patients); mean arterial pressure was allowed to rise during the postbypass phase and returned to prebypass levels in all patients.

Mean arterial blood pressure epochs (30-second periods) were measured. In total, 11,100 epochs were recorded during $\mathrm{CPB}$; 5260 in the alpha-stat and 5840 in the $\mathrm{pH}$-stat groups. The median $\mathrm{TM}<50$ for the alpha-stat group was $628 \mathrm{~min} \mathrm{~mm}$ $\mathrm{Hg}(95 \% \mathrm{CI}, 393$ to $863 \mathrm{~min} \mathrm{~mm} \mathrm{Hg}$ ) and for the pH-stat group it was $379 \mathrm{~min} \mathrm{~mm} \mathrm{Hg}(95 \% \mathrm{CI}, 217$

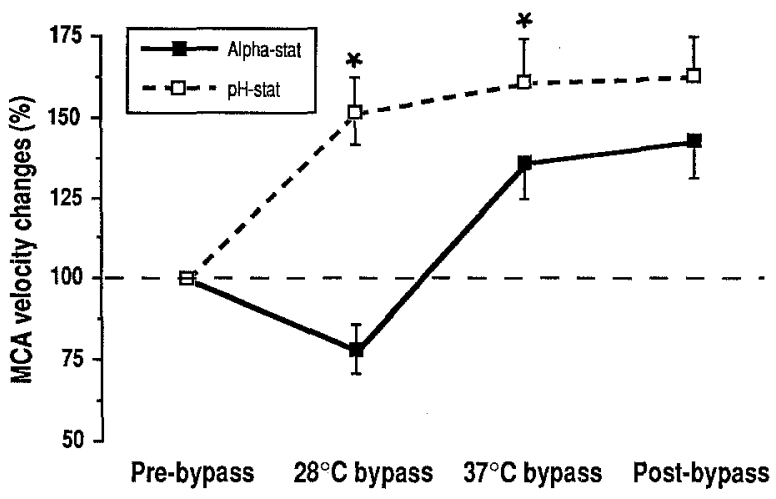

Fig. 2. Changes in the velocity of blood flow in the middle cerebral artery, expressed as percentage of prebypass values during the operation in the alpha-stat and pH-stat groups. Values are mean $\pm 95 \%$ CI. Asterisk, $p<$ 0.05 when compared with those in the alpha-stat group.

to $541 \mathrm{~min} \mathrm{~mm} \mathrm{Hg}$ ); these differences in the $\mathrm{TM}<50$ between the groups did not reach statistical significance $(p=0.09)$.

Nasopharyngeal temperature was also similar between groups during CBF and oxygen metabolism determinations, being approximately $37^{\circ} \mathrm{C}$ at all phases except during the hypothermic bypass phase, when it was reduced to $28^{\circ} \mathrm{C}$.

$\mathrm{PaCO}_{2}$ was normal in both groups during the prebypass, $37^{\circ} \mathrm{C}$, and postbypass phases but was significantly $(p<0.05)$ lower in the alpha-stat group during the hypothermic bypass phase $(26 \mathrm{~mm} \mathrm{Hg}$; $95 \% \mathrm{CI}, 25$ to $27 \mathrm{~mm} \mathrm{Hg}$ ). In accordance with the principles of alpha-stat acid-base control, the blood $\mathrm{pH}$ in this group showed a significant $(p<0.05)$ increase above that of the $\mathrm{pH}$-stat group $(7.53 ; 95 \%$ CI, 7.51 to 7.55 ). Hematocrit values were lower $(20 \%)$ in both groups as a result of hemodilution during the operation and remained low (22\%) during the postbypass phase.

CBF and blood flow velocity changes in the middle cerebral artery. The mean CBF measurements are shown in Fig. 1; significant differences $(p<0.0001)$ between groups occurred only during the $28^{\circ} \mathrm{C}$ bypass phase. In the alpha-stat group, $\mathrm{CBF}$ decreased significantly $(p<0.0001)$, whereas in the $\mathrm{pH}$-stat group the CBF increased significantly $(p<$ 0.0001 ) from the prebypass value. The changes in blood flow velocity in the middle cerebral artery reflected the changes in CBF. The mean changes in blood flow velocity as a percentage of the prebypass values are shown in Fig. 2; the absolute values of blood flow velocity in the middle cerebral artery 


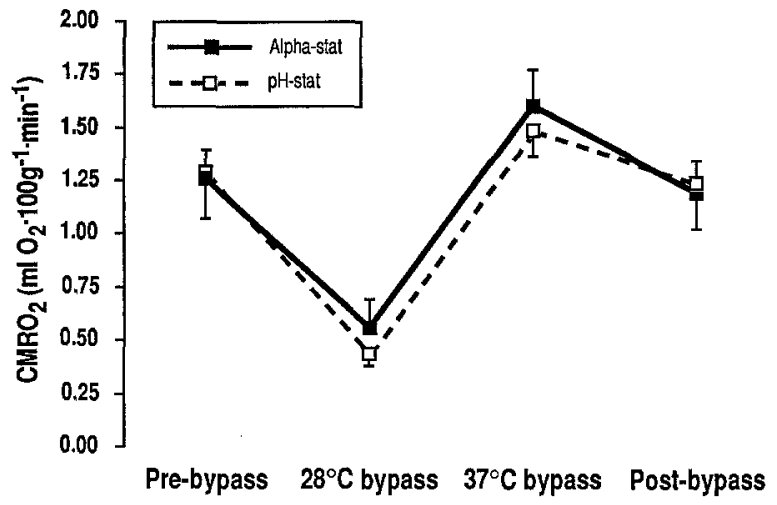

Fig. 3. $\mathrm{CMRO}_{2}$ in the alpha-stat and pH-stat groups during the four phases of the operation. Values are mean $\pm 95 \%$ CI.

were $40 \mathrm{~cm} \cdot \mathrm{sec}^{-1}(95 \% \mathrm{CI}, 35$ to 44$) \mathrm{cm} \cdot \mathrm{sec}^{-1}$ and $43 \mathrm{~cm} \cdot \mathrm{sec}^{-1}$ ( $95 \% \mathrm{CI}, 38$ to $47 \mathrm{~cm} \cdot \mathrm{sec}^{-1}$ ) in the prebypass phase for the $\mathrm{pH}$-stat and alpha-stat groups, respectively. This was increased to $53 \mathrm{~cm}$. $\mathrm{sec}^{-1}\left(95 \% \mathrm{CI}, 53\right.$ to $64 \mathrm{~cm} \cdot \mathrm{sec}^{-1}$ ) in the $\mathrm{pH}$-stat group but decreased to $36 \mathrm{~cm} \cdot \mathrm{sec}^{-1}(95 \% \mathrm{CI}, 31$ to $\left.44 \mathrm{~cm} \cdot \mathrm{sec}^{-1}\right)$ in the alpha-stat group. Significant $(p<0.001)$ increases in CBF and blood flow velocity in the middle cerebral artery (to around $60 \mathrm{~cm}$. $\mathrm{sec}^{-1}$ ) occurred in both groups at $37^{\circ} \mathrm{C}$ before the discontinuation of bypass and after bypass when compared with prebypass values.

Cerebral metabolism. The mean prebypass $\mathrm{CMRO}_{2}$ in the alpha-stat group was $1.26 \mathrm{ml}$ oxygen $\cdot 100 \mathrm{gm}^{-1} \cdot \mathrm{min}^{-1}(95 \% \mathrm{CI}, 1.07$ to 1.45 $\mathrm{ml}$ oxygen $\cdot 100 \mathrm{gm}^{-1} \cdot \mathrm{min}^{-1}$ ); for the $\mathrm{pH}$-stat group, $\mathrm{CMRO}_{2}$ was $1.29 \mathrm{ml}$ oxygen $\cdot 100 \mathrm{gm}^{-1}$. $\min ^{-1}$ (95\% CI, 1.19 to $1.39 \mathrm{ml}$ oxygen $\cdot 100 \mathrm{gm}^{-1}$ $\left.\cdot \min ^{-1}\right)$. During the hypothermic phase of the operation, $\mathrm{CMRO}_{2}$ decreased in both the alphastat and the pH-stat groups of patients (Fig. 3) by $49 \%(95 \% \mathrm{CI}, 40 \%$ to $59 \%)$ and by $63 \%(95 \% \mathrm{CI}$, $53 \%$ to $72 \%$ ), respectively, of the individual prebypass value. $\mathrm{CERO}_{2}$ remained unchanged in the alpha-stat group, whereas in the pH-stat group it decreased significantly $(p<0.0001)$ (Fig. 4). During the hypothermic phase the differences in the two acid-base management protocols were maximal. The $\mathrm{PacO}_{2}$ corrected to core temperature of the patient in the $\mathrm{pH}$-stat group was 40.7 $\mathrm{mm} \mathrm{Hg} \mathrm{(95 \%} \mathrm{CI,} 40.2$ to $41.0 \mathrm{~mm} \mathrm{Hg}$ ) and in the alpha-stat group, $26.0 \mathrm{~mm} \mathrm{Hg}(95 \% \mathrm{CI}, 25.2$ to $26.8 \mathrm{~mm} \mathrm{Hg}$ ).

Neuropsychologic results. Postoperative neuropsychologic deficit (i.e., a deterioration in two or

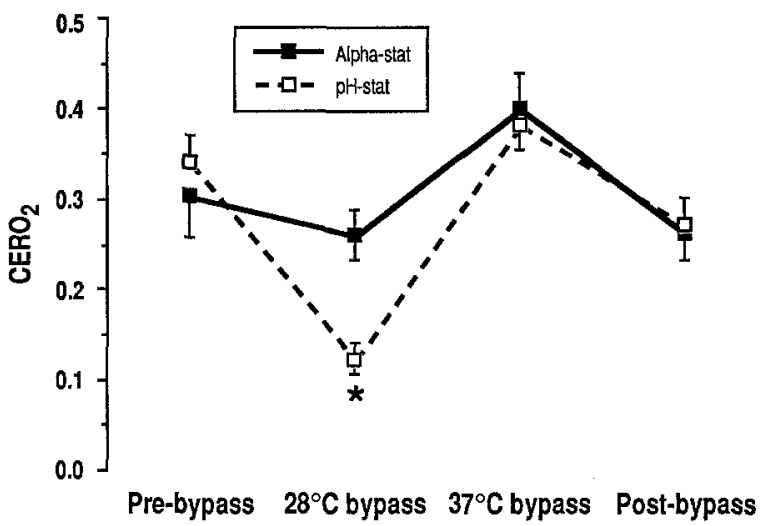

Fig. 4. $\mathrm{CERO}_{2}$ in the alpha-stat and pH-stat groups during the four phases of the operation. Values are mean $\pm 95 \%$ CI. Asterisk, $p<0.05$ when compared with the prebypass value.

more tests) occurred in 16 of the 35 patients ( $45.7 \%$; $95 \%$ CI, $29.2 \%$ to $62.2 \%$ ) in the alpha-stat group compared with 24 of the 35 patients $(68.6 \% ; 95 \%$ $\mathrm{CI}, 53.2 \%$ to $84 \%$; Fisher's exact test $=0.09$ ) in the $\mathrm{pH}$-stat group. Use of a more stringent criterion of deterioration in three or more tests to define overall neuropsychologic impairment makes the difference become more apparent. Neuropsychologic impairment was demonstrated in 17 of 35 patients $(48.6 \%$; $95 \% \mathrm{CI}, 32.0 \%$ to $65.1 \%$ ) in the $\mathrm{pH}$-stat group and in seven of 35 patients $(20 \%$; $95 \% \mathrm{CI}, 6.7 \%$ to $33.2 \%$; Fisher's exact test $=0.02$ ) in the alpha-stat group (Fig. 5). Overall, patients from the $\mathrm{pH}$-stat group showed deficits in a significantly greater number of tests than did the alpha-stat group $(t=2.11$, df $68, p<0.05$, two-tailed test).

A more detailed and sensitive analysis of neuropsychologic tests in intervention studies in cardiac surgery is obtained by comparing group performances on each test. A degree of "learning" would be expected in neuropsychologic tests, and it is against this background in learning that changes should be considered. The differences in the score (change score) for individual patients, that is, postoperative score minus preoperative score for each test, was analyzed. All ten tests were considered separately; with some tests, more than one measure was obtained and these data are presented in Table II. From a total of 17 measurements that were obtained, the performance of patients in the $\mathrm{pH}$-stat group was significantly $(p<0.05)$ worse than that of the alpha-stat group in five of these measurements $(29.4 \% ; 95 \% \mathrm{CI}, 7.8 \%$ to $51.1 \%)$. In the remaining 
12 measurements there was no significant difference in the performance between the groups.

$\mathrm{CBF}$, measured by ${ }^{133} \mathrm{Xe}$ clearance, and percentage change in blood flow velocity in the middle cerebral artery, measured by transcranial Doppler sonography, were assessed for association with the neuropsychologic impairment. The results for the alpha-stat and $\mathrm{pH}$-stat groups are shown in Table III. Neuropsychologic impairment in either group was not associated with variation in CBF. Increased blood flow velocity in the middle cerebral artery during the postbypass period in both the groups was associated with an increased prevalence of neuropsychologic impairment. In addition, in the $\mathrm{pH}$-stat group, an increased blood flow velocity in the middle cerebral artery during bypass at $37^{\circ} \mathrm{C}$ was also associated with neuropsychologic impairment.

Scores for depression and anxiety state were obtained before and after the operation in both groups (Table IV). There were no differences in the Beck depression scores between the groups at either preoperative or postoperative assessments $(p=$ 0.113 and $p=0.197$, respectively). Also, no significant changes occurred in the depression scores on postoperative reassessment in either group. There were no differences in the Spielberger anxiety state scores between the groups at preoperative assessment $(p=0.543)$. These scores decreased significantly in both the alpha-stat and $\mathrm{pH}$-stat groups at postoperative assessment $(p=0.011$ and $p=0.016$, respectively). There was, however, no significant difference between the groups at postoperative assessment $(p=$ 0.171 ). The possibility that the reductions in anxiety state could have influenced the neuropsychologic differences observed between the groups was explored further by calculating the differences in the scores between preoperative and postoperative assessment. There were no significant differences in the degree of reduction of anxiety state between the alpha-stat and the $\mathrm{pH}$-stat groups $(p=0.90)$. Levels of anxiety were found to drop significantly $(p<0.001)$ in both groups after the operation.

\section{Discussion}

Increasing attention is being focused on the more subtle aspects of morbidity after CABG, particularly transient cerebral dysfunction. Such cerebral dysfunction, affecting the finer aspects of higher cortical function, is termed neuropsychologic impairment. This study has focused on the influence of differing acid-base management protocols on $\mathrm{CBF}$, velocity of blood flow in the middle cerebral artery, and the

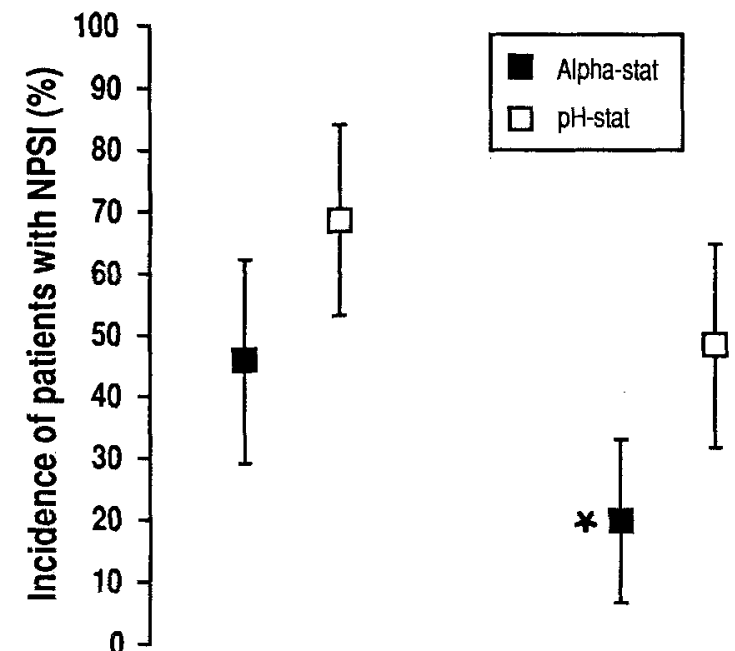

$>2$ test deficit

$>3$ test deficit

Fig. 5. Severity of neuropsychologic impairment (NPSI) in alpha-stat and pH-stat groups for both two-test and three-test deficits. Values are mean $\pm 95 \% \mathrm{CI}$. Asterisk, $p<0.05$ when compared with the prebypass value.

association of changes in these blood flow measurements and $\mathrm{CBF}$ autoregulation on neuropsychologic outcome after CABG.

The two most commonly used acid-base protocols adopted during hypothermic CPB are alpha-stat and $\mathrm{pH}$-stat management. ${ }^{26,27}$ The two protocols differ markedly in the handling of total carbon dioxide content, which is reflected in widely differing effects on the cerebral circulation. During $\mathrm{pH}$-stat management, $\mathrm{pH}$ and $\mathrm{PaCO}_{2}$ are maintained at 7.4 and 40 $\mathrm{mm} \mathrm{Hg}$, respectively, corrected to the core temperature of the patient by addition of carbon dioxide during cooling. By contrast, with alpha-stat management $\mathrm{PaCO}_{2}$ is not corrected to body temperature. It decreases, with consequent increase in $\mathrm{pH}$, preserving intracellular neutrality and net protein charge states of the histidine plasma proteins. ${ }^{28,29}$

The influence of acid-base on CBF and metabolism. This study has shown that, irrespective of the acid-base management protocol, $\mathrm{CMRO}_{2}$ decreases during the hypothermic phase of CPB. To maintain flow-metabolism coupling, a corresponding reduction in blood flow should occur. During hypothermic CPB with alpha-stat management, both CBF (measured in absolute terms by ${ }^{133} \mathrm{Xe}$ clearance) and blood flow velocity in the middle cerebral artery (measured by transcranial Doppler sonography) decreased by $18 \%$ and $13 \%$, respectively, whereas $\mathrm{pH}$-stat management increased $\mathrm{CBF}$ and blood flow 
Table II. Change in the neuropsychologic test scores in the alpha-stat and pH-stat groups

\begin{tabular}{|c|c|c|c|c|c|c|}
\hline \multirow[b]{2}{*}{ Test } & \multicolumn{2}{|c|}{ Alpha-stat } & \multicolumn{2}{|c|}{$p H$-stat } & \multicolumn{2}{|c|}{$t$ Test } \\
\hline & Mean & $95 \% \mathrm{CI}$ & Mean & $95 \% \mathrm{CI}$ & $t$ Value & $P$ Value \\
\hline \multicolumn{7}{|l|}{ Letter cancellation } \\
\hline Time (sec) & 3.3 & -6.1 to 12.7 & 2.7 & -9.6 to 15.0 & 0.09 & 0.93 \\
\hline Errors & -1.7 & -2.6 to -0.8 & 0.1 & -1.1 to 1.4 & -2.44 & 0.02 \\
\hline Trail Making A (sec) & -2.2 & -6.0 to 1.6 & 1.1 & -3.2 to 5.4 & -1.18 & 0.24 \\
\hline Trail Making B (sec) & -11.6 & -22.6 to -0.5 & 17.1 & -4.4 to 38.6 & -2.41 & 0.019 \\
\hline \multicolumn{7}{|l|}{ Purdue Pegboard } \\
\hline Dominant hand & 1.2 & 0.4 to 2.0 & -0.7 & -1.4 to 0.02 & 3.63 & 0.0005 \\
\hline Nondominant hand & 0.8 & 0.1 to 1.5 & 0.2 & -0.6 to 1.0 & 1.21 & 0.23 \\
\hline Both hands together & 0.3 & -0.4 to 0.9 & 0.4 & -0.2 to 1.0 & -0.20 & 0.84 \\
\hline \multicolumn{7}{|c|}{ Rey auditory verbal memory } \\
\hline Trial 1 & 0.4 & -0.2 to 0.9 & 0.3 & -0.5 to 1.1 & 0.12 & 0.90 \\
\hline Trial 5 & 0.4 & -0.4 to 1.2 & -0.8 & -1.6 to 0.04 & 2.09 & 0.04 \\
\hline Trial 7 & -0.3 & -1.5 to 0.8 & -1.2 & -2.0 to -0.4 & 1.28 & 0.20 \\
\hline Block design & 2.2 & 0.5 to 3.8 & -0.5 & -2.3 to 1.2 & 2.30 & 0.02 \\
\hline \multicolumn{7}{|l|}{ Symbol digit replacement } \\
\hline Time (sec) & -0.2 & -0.4 to -0.1 & -0.1 & -0.4 to 0.2 & -0.94 & 0.35 \\
\hline Correct & 0.5 & -0.6 to 1.7 & -0.3 & -2.1 to 1.5 & 0.82 & 0.42 \\
\hline \multicolumn{7}{|l|}{ Choice reaction } \\
\hline Time (sec) & 0.03 & 0 to 0.1 & 0.04 & 0 to 0.1 & -0.17 & 0.86 \\
\hline Correct & -0.03 & -0.5 to 0.5 & -0.5 & -2.6 to 1.6 & 0.43 & 0.67 \\
\hline \multicolumn{7}{|l|}{ Nonverbal memory } \\
\hline Test 1 correct & 0 & -0.6 to 0.6 & -0.1 & -0.8 to 0.7 & 0.12 & 0.90 \\
\hline Test 2 correct & 0.1 & -0.4 to 0.7 & 0.1 & -0.5 to 0.7 & 0 & 1 \\
\hline
\end{tabular}

The postoperative score in each test was subtracted from the preoperative score for individual patients

velocity in the middle cerebral artery by $48 \%$ and $53 \%$, respectively. Thus cerebral perfusion levels with pH-stat management were well above those necessary to maintain adequate cerebral metabolism. Similarly, profound decrease in $\mathrm{CERO}_{2}$, reflected by an increased oxygen content in cerebral effluent blood, was demonstrated in the $\mathrm{pH}$-stat group; matching of oxygen demand to oxygen extraction was far nearer to the "normal" values $(0.30$ to 0.45 ), as suggested by Murkin, ${ }^{30}$ in the alpha-stat group. This observation agrees with those of other authors who have addressed the question of minimum extracorporeal circulation flow rates necessary to match cerebral demand for oxygen during hypothermic CPB. ${ }^{31,32}$ These contrasting patterns of CBF cannot be attributed to differences in pump flow, mean arterial pressure, hemodilution, or temperature, because there were no differences in these variables during measurement of $\mathrm{CBF}$ and metabolism. Additionally, the two methods of CBF assessment followed an identical trend.

Although CBF decreases during the hypothermic phase of CPB in the alpha-stat group, is this reduction appropriate to the reduced metabolic demands by the brain? The current study has shown that some cerebral hyperperfusion was still observed during alpha-stat management because $\mathrm{CMRO}_{2}$ was reduced by $49 \%$ whereas CBF decreased by only $18 \%$. This slight mismatch is reflected by the $\mathrm{CERO}_{2}$ remaining reduced in this group of patients during hypothermia. Although alpha-stat management offers significantly better coupling of flow to metabolism than does $\mathrm{pH}$-stat, complete matching in terms of oxygen demand is still not entirely achieved.

In the current study, CBF altered by $1.1 \mathrm{ml} \cdot 100$ $\mathrm{gm}^{-1} \cdot \mathrm{min}^{-1} \cdot \mathrm{mm} \mathrm{Hg}^{-1}$ difference in $\mathrm{PacO}_{2}$, which was similar to results obtained by Johnsson and coworkers $^{33}\left(1.2 \mathrm{ml} \cdot 100 \mathrm{gm}^{-1} \cdot \mathrm{min}^{-1} \cdot \mathrm{mm} \mathrm{Hg}^{-1}\right)$ and by Prough and colleagues ${ }^{15}(1.07 \mathrm{ml} \cdot 100$ $\left.\mathrm{gm}^{-1} \cdot \mathrm{min}^{-1} \cdot \mathrm{mm} \mathrm{Hg}^{-1}\right)$. As shown in our study and in others, ${ }^{13,34}$ a significant correlation between changes in $\mathrm{PacO}_{2}$ and both $\mathrm{CBF}$ and blood flow velocity in the middle cerebral artery from before bypass to hypothermic $\left(28^{\circ} \mathrm{C}\right)$ bypass lends support to the long-established knowledge that $\mathrm{CBF}$ is profoundly influenced by changes in $\mathrm{PacO}_{2}$ and that this response to carbon dioxide by $\mathrm{CBF}$ continues during moderately hypothermic CPB.

The importance of differing acid-base protocols has been overlooked in many studies of CBF during $\mathrm{CPB}$, leading to widely differing conclusions. Henriksen, Hjelms, and Lindeburgh ${ }^{35}$ speculated that cere- 
Table III. Neuropsychologic outcome in the alpha-stat and the pH-stat groups in relation to cerebral blood flow $(C B F)$ and middle cerebral artery blood flow velocity (MCAFV)

\begin{tabular}{|c|c|c|c|c|c|c|c|c|}
\hline & \multicolumn{4}{|c|}{ Alpha-stat group } & \multicolumn{4}{|c|}{ pH-stat group } \\
\hline & \multicolumn{2}{|c|}{$\left(\mathrm{ml} \cdot 100 \mathrm{gm}^{-1} \cdot \mathrm{min}^{-1}\right)$} & \multicolumn{2}{|c|}{$\begin{array}{c}M C A F V \\
(\%)\end{array}$} & \multicolumn{2}{|c|}{$\begin{array}{c}C B F \\
\left(m l \cdot 100 \mathrm{gm}^{-1} \cdot \mathrm{min}^{-1}\right)\end{array}$} & \multicolumn{2}{|c|}{$\begin{array}{c}M C A F V \\
(\%)\end{array}$} \\
\hline & Mean & $p$ Value & Mean & $p$ Value & Mean & p Value & Mean & $p$ Value \\
\hline \multicolumn{9}{|l|}{ Prebypass } \\
\hline Normal & 29.2 & 0.899 & 100 & & 28.6 & 0.549 & 100 & \\
\hline Impaired & 29.5 & & 100 & & 27.3 & & 100 & \\
\hline \multicolumn{9}{|l|}{$28^{\circ} \mathrm{C}$ bypass } \\
\hline Normal & 23.9 & 0.971 & 85 & 0.801 & 42.3 & 0.474 & 140 & 0.114 \\
\hline Impaired & 23.9 & & 87 & & 42.7 & & 157 & \\
\hline \multicolumn{9}{|l|}{$37^{\circ} \mathrm{C}$ bypass } \\
\hline Normal & 45.0 & 0.609 & 136 & 0.434 & 43.7 & 0.733 & 137 & 0.010 \\
\hline Impaired & 43.5 & & 144 & & 42.6 & & 168 & \\
\hline \multicolumn{9}{|l|}{ Postbypass } \\
\hline Normal & 42.6 & 0.096 & 133 & 0.019 & 44.6 & 0.826 & 142 & 0.015 \\
\hline Impaired & 48.0 & & 159 & & 45.5 & & 174 & \\
\hline
\end{tabular}

The prebypass MCAFV was normalized to $100 \%$ and other values were expressed as a percentage of this. Normal, Patients who have failed none or one of the ten neuropsychologic tests. Impaired, Patients who have failed two or more of the ten neuropsychologic tests.

bral hyperperfusion was due to hyperemia after transitory diffuse microvascular blockade of the cerebral vasculature, but the hyperemia observed in their study occurred from the onset of $\mathrm{CPB}$, suggesting something other than microvascular damage. In this study and others, ${ }^{15,16,36}$ hyperperfusion is dependent on pH-stat acid-base regulation, achieved by an absolutely higher $\mathrm{PaCO}_{2}$ than for alpha-stat, and it is this that causes hyperperfusion during $\mathrm{pH}$-stat management.

There is a discrepancy in the literature in the degree of change in $\mathrm{CBF}$ within the two groups during hypothermia. For $\mathrm{pH}$-stat management, $\mathrm{CBF}$ has been reported to increase by $0 \%$ to $28 \%,{ }^{16}$ by $91 \%,{ }^{36}$ and by $48 \%$ in the present study. Similar temperatures $\left(28^{\circ} \mathrm{C}\right), \mathrm{PacO}_{2}$ levels, and intravenous anesthetic techniques were used, but the differences in the depth of anesthesia may have accounted for some of the differences. Alternatively, mean arterial pressure during measurements of $\mathrm{CBF}$ may explain these discrepancies. Loss of autoregulation during $\mathrm{pH}$-stat management, resulting in pressure-passive CBF, has been reported. ${ }^{15,30,37}$ Stephan and coworkers ${ }^{36}$ reported a mean arterial pressure of $70 \pm$ $11 \mathrm{~mm} \mathrm{Hg}$ with CBF in this group, varying from 39 to $180 \mathrm{ml} \cdot 100 \mathrm{gm}^{-1} \cdot \mathrm{min}^{-1}$, whereas CBF measurements in the present study at a mean arterial pressure of $50 \pm 3 \mathrm{~mm} \mathrm{Hg}$ varied from 26 to 50 $\mathrm{ml} \cdot 100 \mathrm{gm}^{-1} \cdot \mathrm{min}^{-1}$.

Using alpha-stat management, Stephan's group ${ }^{36}$ reported a reduction in CBF of $14 \%$, similar to that
Table IV. Beck Depression Score and Speilberger Anxiety State Score for patients in the alpha-stat and pH-stat groups

\begin{tabular}{|c|c|c|c|c|c|c|}
\hline & \multicolumn{3}{|c|}{ Alpha-stat } & \multicolumn{3}{|c|}{$p H$-stat } \\
\hline & & $95 \%$ & $p$ & & $95 \%$ & $p$ \\
\hline & Mean & $C I$ & Value & Mean & $C I$ & Value \\
\hline \multicolumn{7}{|c|}{ Beck Depression Score } \\
\hline Preop. & 8 & $6-10$ & 0.268 & 10 & $8-11$ & 0.252 \\
\hline Postop. & 7 & $6-9$ & & 9 & $7-11$ & \\
\hline \multicolumn{7}{|c|}{$\begin{array}{c}\text { Speilberger Anxiety } \\
\text { State Score }\end{array}$} \\
\hline Preop. & 36 & $33-40$ & 0.011 & 38 & $35-41$ & 0.016 \\
\hline Postop. & 32 & $28-35$ & & 35 & $32-38$ & \\
\hline
\end{tabular}

$(18 \%)$ observed in the current study. In contrast, decreases in $\mathrm{CBF}$ of $55 \%^{12}$ and $45 \%$ to $70 \%{ }^{16}$ have been observed; these discrepancies are unlikely to be caused by blood pressure variations, because cerebral vascular autoregulation is better preserved during alpha-stat regulation..$^{16,37,38}$ One possibility may be the method, type, or quantity of pharmacologic agents used to attain the desired perfusion pressure. We used metaraminol and phentolamine to maintain pressures around $50 \mathrm{~mm} \mathrm{Hg}$; Stephan's group ${ }^{36}$ varied the perfusion flow rates to maintain pressure between 60 and $100 \mathrm{~mm} \mathrm{Hg}$; and Govier and colleagues ${ }^{12}$ used sodium nitroprusside, droperidol, or phenylephrine to maintain pressures between 45 and $70 \mathrm{~mm} \mathrm{Hg}$. 
The technique of CBF measurement may also be responsible for some of the variations. Evaluation of CBF in different regions of the brain has been shown to be heterogeneous. ${ }^{39}$ The ${ }^{133} \mathrm{Xe}$ clearance technique with biparietal collimated scintillation probes was used in this study and the study reported by Grovier's group. ${ }^{12}$ Alternatively, Murkin ${ }^{30}$ used 10 scintillation probes for ${ }^{133} \mathrm{Xe}$ clearance detection, and the CBF values were averaged as mean hemispheric flows, whereas Stephan and coworkers ${ }^{36}$ used the argon wash-in technique. We took particular care to obtain similar sampling sites, but this is unlikely to have been exact for all patients; this feature becomes even more important when comparisons are made with other studies at different institutions. Normalization of prebypass values does reduce these variations but cannot eliminate them completely.

In the current study, there was a significantly greater reduction in $\mathrm{CMRO}_{2}$ in the $\mathrm{pH}$-stat group during hypothermia, which agrees with similar findings by Prough and coworkers. ${ }^{40}$ This would be in keeping with the pH-stat theory of an additional reduction in metabolic rate, over and above that which is achieved by hypothermic depression of enzymatic activity, as a consequence of relative intracellular acidosis. ${ }^{28,29}$ These differences during hypothermia were not, however, evident in the clinical comparative studies reported by Stephan, ${ }^{36}$ Murkin, ${ }^{16}$ and their associates. Perhaps the wide variation in both perfusion pressures and $\mathrm{PacO}_{2}$ evident in both these studies could account for these differences. This would influence CBF and, in turn, the calculated $\mathrm{CMRO}_{2}$ values.

Neuropsychologic impairment. The incidence of neuropsychologic impairment found in the present study in the alpha-stat and $\mathrm{pH}$-stat groups agrees with findings in earlier studies. ${ }^{3,4,41}$ However, we have shown that the severity of neuropsychologic impairment was significantly lower in the alpha-stat group than the $\mathrm{pH}$-stat group. In contrast, Bashein and colleagues ${ }^{21}$ showed no difference in the prevalence of neuropsychologic impairment in 86 patients undergoing cardiac operations. Their patients were randomly assigned to alpha-stat and $\mathrm{pH}$-stat groups. They were neuropsychologically assessed (with an eleven-test battery) before the operation, and the tests were repeated at 8 days and 7 months after the operation. The reliability of measuring neuropsychologic impairment within a few days of the operation remains controversial, with several studies showing high incidences (55\% to $70 \%$ ) of impairment $^{3,4,6,8,41}$ and others ${ }^{1,10}$ showing lower incidences (18\% to $28 \%$ ). Early neuropsychologic assessment is influenced by a certain amount of general postoperative disturbance, such as tiredness, pain, and analgesic effects. What remains clear, however, is that a proportion of patients undergoing CABG do have short-term neuropsychologic changes in almost all studies. The incidence of neuropsychologic impairment at 8 weeks, ${ }^{1,3,4} 6$ months, ${ }^{2,41}$ and 1 year after the operation ${ }^{8,42}$ is lower than the early postoperative incidence. Bashein and colleagues ${ }^{21}$ observed no differences between groups 7 months after the operation; however, the study groups consisted of patients undergoing both open cardiac procedures and $\mathrm{CABG}$. Although the prevalence of the procedures was similar in the two groups, the etiologic mechanisms for neurologic impairment may not be the same. Bashein's results may have been confounded by these variables, inasmuch as macroemboli (either gaseous or particulate) are a well-documented cause of neurologic damage. In Bashein's study, the differences in $\mathrm{PaCO}_{2}$ and $\mathrm{pH}$ values were rather narrow, probably from higher body temperatures, and though conforming to the principles of alpha-stat and $\mathrm{pH}$-stat, the effects on cerebral perfusion would have been less marked. CBF was not measured in Bashein's study; thus the interrelationship between cognitive function, acid-base management, and CBF is impossible to assess. The question of whether inappropriate cerebral perfusion is an important factor in postoperative cognitive deficit remained unanswered from this study.

Potential instigators of cerebral injury. The present understanding on the instigators of cerebral damage after CABG rests on two broad premises: inappropriate cerebral perfusion and microembolization during CPB. Embolic phenomena occur during $\mathrm{CPB},{ }^{18,19}$ and microemboli are currently considered to be among the main instigators of neuropsychologic impairment after CABG ${ }^{17,20}$ It is possible that many of the imperfections and alterations in CBF during CPB, induced by the altered acid-base management of the patient during $\mathrm{CPB}$, may influence the microembolic delivery to the brain; this, in turn, could influence the neuropsychologic outcome. The occurrence of cerebral microembolism during CPB has been appreciated for some time. Blauth and associates,${ }^{17}$ using retinal fluorescein photography, revealed microembolic occlusion of portions of the retinal microcirculation in patients undergoing routine CABG. Although microembolic events were not measured in the present 
study, it is not unreasonable to extrapolate that what is occurring in the circulation of the retina is simultaneously occurring in the microcirculation of the brain and may be responsible for neuronal damage and overall cerebral impairment. Microembolic events during CPB have also been reported by other authors using transcranial Doppler sonography of the middle cerebral artery. ${ }^{18,20}$ These studies offer further evidence that microemboli generated during CPB may be among the important mediators of brain damage. If the model of microembolic damage, as an important etiologic agent in perioperative cerebral damage, is correct, then periods of unnecessary cerebral hyperperfusion, as evident in the $\mathrm{pH}$-stat management regimen, can no longer be seen as a potential safety cushion against cerebral ischemia; rather, they may be periods of possible increase in microembolic damage.

The data from this study would support modification of the acid-base protocol adopted during hypothermic $\mathrm{CPB}$ from the widely practiced temperature-corrected method of $\mathrm{pH}$-stat to the temperature-uncorrected method of alpha-stat.

\section{Limitations of the study}

Neuropsychologic measurement techniques. The neuropsychologic tests were conducted by two examiners (R.L.P. and D.N.J.) to complete the study within the scheduled period. Ideally, one examiner should conduct all tests. An assumption has been made in this study that the experience of the examiners would have affected both groups equally.

The management of the acid-base protocol during the operation and the postoperative neuropsychologic assessment was undertaken by one of us (R.L.P.). Consequently, blinding in this study was practiced to the point that information regarding the allocation of the acid-base strategy used for patients was not available to the conductor during the repeat neuropsychologic test assessment. Moreover, the neuropsychologic tests demand no interpretation by the conductor.

The method of analysis may impose a sensitivity bias for detection of cerebral injury at the expense of decreased specificity by the following means: (1) a probability of type 1 errors, (2) introduction of bias by assessing changes in one direction only, (3) ignoring the magnitude of changes beyond 1 standard deviation, (4) defining the patient's status as impaired when most test scores actually improved, (5) loss of statistical power by dichotomizing, thereby eliminating the possibility of determining associations. We have chosen to examine the change in individual performance over time, with each patient acting as his or her own control.

Neurologic assessment. Although neurologic assessments were not performed by a neurologist, this study only undertook to evaluate focal deficits. It is unlikely, therefore, that these deficits would have remained unrecognized.

$C B F$ measurements. A major limitation relates to the invasiveness of the technique. Meticulous care is required to remove air from the syringe and to avoid lifting atheromatous plaques in the carotid artery. Disturbances at the time of injections were seen in all patients during continuous transcranial Doppler monitoring. Small errors (of up to $2 \%$ ) caused by ${ }^{133} \mathrm{Xe}$ recirculation were disregarded in this study. Distribution of ${ }^{133} \mathrm{Xe}$ to tissues other than the brain (for example, the scalp) are small and were also disregarded in this study. Background and remaining activity of previous ${ }^{133} \mathrm{Xe}$ was minimized by using appropriate correction factors within the Novocerebrograph microprocessor.

Limitations of transcranial Doppler sonographic measurements. The assumption has been made that the diameter of the basal cerebral arteries and its flow profile remain constant with changing flow patterns and temperatures during surgery. A major practical problem is the need to maintain a constant angle between the ultrasonic wall and the vessel wall. Slight displacement of the probe resulted in loss of the insonation point, necessitating careful repositioning of the probe. To counteract this, a holder for the probe was designed and used in this study.

As a consequence of these limitations, a certain amount of error has been accepted in this study and the results must be viewed with these limitations in mind.

\section{Conclusions}

The data from this study would support modification of the acid-base protocol adopted during hypothermic CPB from the temperature-corrected method of $\mathrm{pH}$-stat to the temperature-uncorrected method of alpha-stat. Considering the differences between the current study and previous studies regarding neuropsychologic outcome, further studies are warranted to attempt to resolve this dilemma.

\section{REFERENCES}

1. Savageau JA, Stanton BA, Jenkins CD, Klein MD. Neuropsychological dysfunction following elective cardiac operation. I. Early assessment. J Thorac Cardiovasc Surg 1982;84: 585-94. 
2. Savageau JA, Stanton BA, Jenkins CD, Frater RW. Neuropsychological dysfunction following elective cardiac operation. II. A six-month reassessment. J Thorac Cardiovasc Surg 1982;84:595-600.

3. Shaw PJ, Bates D, Cartlidge NE, et al. Early intellectual dysfunction following coronary artery bypass surgery. Q J Med 1986;58:59-68.

4. Smith PLC, Treasure T, Newman SP, et al. Cerebral consequences of cardiopulmonary bypass. Lancet 1986;1:823-5.

5. Newman S. The incidence and nature of neuropsychological morbidity following cardiac surgery. Perfusion 1989;4:93-100.

6. Treasure T, Smith PL, Newman S, et al. Impairment of cerebral function following cardiac and other major surgery. Eur J Cardiothorac Surg 1989;3:216-21.

7. Townes BD, Bashein G, Hornbein TF, et al. Neurobehavioural outcomes in cardiac operations: a prospective controlled study. J Thorac Cardiovasc Surg 1989;98:774-82.

8. Venn GE, Klinger L, Newman S, Harrison M, Ell PJ, Treasure T. The neuropsychological sequelae of bypass 12 months following coronary artery surgery. Br Heart J 1987;57:565.

9. Sotaniemi KA, Mononen H, Hokkanen TE. Long-term cerebral outcome after open-heart surgery: a five-year neuropsychological follow-up study. Stroke 1986;17:410-6.

10. Nevin M, Colchester AC, Adams S, Pepper JR. Evidence for involvement of hypocapnia and hypotension in aetiology of neurological deficit after cardiopulmonary bypass. Lancet 1987;2:1493-5.

11. Pugsley WB, Klinger L, Paschalis C, Newman SN, Harrison $M$, Treasure T. Does arterial line filtration affect the bypass related cerebral impairment observed in patients undergoing coronary artery surgery? Clin Sci 1988;75(Suppl 19):30-1.

12. Govier AV, Reves JG, McKay RD, et al. Factors and their influence on regional cerebral blood flow during nonpulsatile cardiopulmonary bypass. Ann Thorac Surg 1984;38:592-600.

13. Henriksen $\mathbf{L}$. Brain luxury perfusion during cardiopulmonary bypass in humans: a study of the cerebral blood flow response to changes in $\mathrm{CO}_{2}, \mathrm{O}_{2}$, and blood pressure. J Cereb Blood Flow Metab 1986;6:366-78.

14. Venn GE, Sherry K, Klinger L, et al. Cerebral blood flow during cardiopulmonary bypass. Eur J Cardiothorac Surg 1988;2:360-3.

15. Prough DS, Stump DA, Roy RC, et al. Response of cerebral blood flow to changes in carbon dioxide tension during hypothermic cardiopulmonary bypass. Anesthesiology 1986; 64:576-81.

16. Murkin JM, Farrar JK, Tweed WA, McKenzie FN, Guiraudon $G$. Cerebral autoregulation and flow/metabolism coupling during cardiopulmonary bypass: the influence of $\mathrm{Paco}_{2}$. Anesth Analg 1987;66:825-32.

17. Blauth CI, Arnold JV, Schulenberg WE, McCartney AC, Kohner EM, Taylor KM. Cerebral microembolism during cardiopulmonary bypass: retinal microvascular studies in vivo with fluorescein angiography. J Thorac Cardiovasc Surg 1988;95:668-76.

18. Deverall PB, Padayachee TS, Parsons S, Theobald R, Battistessa SA. Ultrasound detection of microemboli in the middle cerebral artery during cardiopulmonary bypass surgery. Eur J Cardiothorac Surg 1988;2:256-60.

19. Moody DM, Bell MA, Challa VR, Johnston WE, Prough DS. Brain microemboli during cardiac surgery or aortography. Ann Neurol 1990;28:475-6.

20. Pugsley W, Klinger L, Paschalis C, Newman S, Harrison M,
Treasure T. Microemboli and cerebral impairment during cardiac surgery. Vase Surg 1990;24:34-43.

21. Bashein G, Townes BD, Nessly ML, et al. A randomized study of carbon dioxide management during hypothermic cardiopulmonary bypass. Anesthesiology 1990;72:7-15.

22. Stockard JJ, Bickford RG, Schauble JF. Pressure-dependent cerebral ischaemia during cardiopulmonary bypass. Neurology 1973;23:521-9.

23. Chen RYZ, Fan F, Kim S, Jan KM, Usami S, Chien S. Tissue-blood partition coefficient for xenon: temperature and hematocrit dependence. J Appl Physiol 1980;49:178-83.

24. Aaslid R, Markwalder TM, Nornes H. Noninvasive transcranial Doppler ultrasound recording of flow velocity in basal cerebral arteries. J Neurosurg 1982;57:769-74.

25. Grabielsen TO, Greitz T. Normal size of internal carotid, middle cerebral and anterior cerebral arteries. Acta Radiol Diagn 1970;10:1-10.

26. Groom RC, Hill AG, Akl BF, Lefrak EA, Kurusz M. Pediatric perfusion survey. Proc Am Acad Cardiovasc Perf 1990;11:78-84.

27. Patel R, Alston RP. Anaesthesia and cardiopulmonary bypass: a UK and Ireland survey. Perfusion 1993;8:313-9.

28. Swan H. The importance of acid-base management for cardiac and cerebral preservation during open heart operations. Surg Gynecol Obstet 1984;158:391-414.

29. Swain JA. Acid-base status, hypothermia and cardiac surgery. Perfusion 1986;1:231-8.

30. Murkin JM. Cerebral hyperperfusion during cardiopulmonary bypass: the influence of $\mathrm{Paco}_{2}$. In: Hilberman $\mathrm{M}$, ed. Brain injury and protection during heart surgery. Boston: Maritinus Nijhoff, 1988:47-66.

31. Miyamoto K, Kawashima Y, Matsuda H, Okuda A, Hirose $H$. Optimal perfusion flow rate for the brain during deep hypothermic cardiopulmonary bypass at $20^{\circ} \mathrm{C}$ : an experimental study. J Thorac Cardiovasc Surg 1986;92:1065-70.

32. Swain JA, McDonald TJ, Griffith PK, Balaban RS, Clark RE, Ceckler T. Low-flow hypothermic cardiopulmonary bypass protects the brain. J Thorac Cardiovasc Surg 1991;102:76-84.

33. Johnsson P, Messeter K, Ryding E, Kugelberg J, Stabl E Cerebral vasoreactivity to carbon dioxide during cardiopulmonary perfusion at normothermia and hypothermia. Ann Thorac Surg 1989;48:769-75.

34. Kern F, Greeley W, Ungerleider R, Reves J. Cerebral blood flow increases in response to elevations in $\mathrm{PaCO}_{2}$ in children during hypothermic cardiopulmonary bypass. $\mathrm{J}$ Thorac Cardiovasc Surg 1991;101:618-22.

35. Henriksen L, Hjelms E, Lindeburgh T. Brain hyperperfusion during cardiac operations. J Thorac Cardiovasc Surg 1983; 86:202-9.

36. Stephan H, Weyland A, Kazmaier S, Henze T, Menck S, Sonntag H. Acid-base management during hypothermic cardiopulmonary bypass does not affect cerebral metabolism but does affect blood flow and neurological outcome. $\mathrm{Br}$ J Anaesth 1992;69:51-7.

37. Patel RL, Turtle MRJ, Chambers DJ, Venn GE. Effect of differing acid-base regulation on cerebral blood flow autoregulation during cardiopulmonary bypass. Eur $\mathbf{J}$ Cardiothorac Surg 1992;6:302-7.

38. Johnsson P, Messeter K, Ryding E, Nordstrom L, Stahl E Cerebral blood flow and autoregulation during hypothermic cardiopulmonary bypass. Ann Thorac Surg 1987;43:386-90. 
39. Wilkinson I, Buil J, DuBoulay G, Marshall J, Ross Russell $\mathrm{R}$, Symon L. The heterogeneity of blood flow throughout the normal cerebral hemisphere. In: Brock M, Fieschi C, Ingvar D, Lassen N, Schurmann K, eds. Cerebral blood flow: clinical and experimental results. Berlin: SpringerVerlag, 1969:17-8.

40. Prough DS, Rogers AT, Stump DA, Mills SA, Gravlee GP, Taylor C. Hypercarbia depresses cerebral oxygen consumption during cardiopulmonary bypass. Stroke 1990;21:1162-6.

41. Shaw PJ, Bates D, Cartlidge NE, et al. Long-term intellectual dysfunction following coronary artery bypass graft surgery: a six month follow-up study. Q J Med 1987;62:259-68.

42. Stump DA, Newman SP, Coker LH, Phipps JM, Miller CC. Persistence of neuropsychological deficits following CABG. Anesthesiology 1990;73:A113.

43. Taylor E. The appraisal of children with cerebral deficits. New York: Harvard University Press, 1959.

44. Rey A. L'examen clinique en psychologie. Paris: Presses Universitaires de France, 1964.

45. Reitan RM. Trail Making Test: manual for administration, scoring and interpretation. Indianapolis: Indiana University Medical Center, 1958.

46. Lezak M. Neuropsychological assessment. Oxford: Oxford University Press, 1983.

47. Smith A. The symbol Digit Modalities Test: A neuropsychologic test for economic screening of learning and other cerebral disorders. Learning Disorders 1968;3:83-91.

48. Weschler D. Instruction manual for the Weschler Memory Scale. New York: Psychological Corps, 1945.

49. Beck AT, Ward CH, Mendelson M, Mock J, Baugh J. An inventory for measuring depression. Arch Gen Psychiatry 1961;4:561-71.

50. Weschler D. Weschler Adult Intelligence Scale Manual. New York: Psychological Corps, 1955.

\section{Appendix}

\section{Neuropsychologic test details}

Memory. Verbal memory was assessed by means of the Rey Auditory Verbal Learning test, which consists of a free recall task of a word list of fifteen items. The list was repeated on five occasions, followed by a new list and then a final additional recall of the original list. ${ }^{43,44}$

Nonverbal memory was assessed by a computer-administered test system and consisted of a checkerboard design presented to the patient for 10 seconds followed by three designs, one of which was identical to the original. Two tests were performed at different levels of difficulty, each with fifteen designs. The number of correct responses and the speed of response were recorded.
Attention and concentration. Attention and concentration were tested by two Trail Making tests ( $A$ and $B$ ), a Letter Cancellation Task, a Choice Reaction Task, and the Symbol Digit Replacement test. In the Trail Making tests, ${ }^{45}$ the individual had to draw lines to connect consecutively numbered circles (part A) and consecutively numbered and lettered circles (part B) as rapidly as possible. The time taken to complete the tests was recorded. In the Letter Cancellation Task the subject was required to work as quickly as possible through an array of 90 letters, crossing out every occurrence of the letter $P$. Both errors and time of completion were recorded. The Choice Reaction Task ${ }^{46}$ was conducted on a microcomputer. Each subject had to respond as quickly as possible to the letter $A$ or $B$ by pressing an appropriate key on the keyboard. The mean reaction time and errors acquired were recorded. The Symbol Digit Replacement test ${ }^{47}$ was also automated on a microcomputer. In this test the subject had to "type" the appropriate number corresponding to a particular symbol. After twenty practice trials, 50 test items were presented and both completion time and errors acquired were recorded.

Perceptuo-motor ability. For perceptuo-motor ability the Purdue Pegboard task was performed. In this exercise the subject had to place as many pegs as possible into a line of holes, one at a time, in 30 seconds. The first trial used the preferred hand, the second trial used the nonpreferred hand, and the final trial used both hands simultaneously.

Visuo-spatial ability. For visuo-spatial ability the block design subset of the Weschler Adult Intelligence Scale test $^{48}$ was performed.

Patients were also evaluated at both times of neuropsychologic assessment for depression by means of the Beck Depression Inventory. ${ }^{49}$ This assessment was automated on an Apple LC microcomputer, and the task for the patient was to choose one of five alternatives that best described his or her mood. Twenty various aspects of mood were tested with the use of this inventory. During both preoperative and postoperative neuropsychologic examination, the patient's anxiety state was measured by means of the Spielberger State Anxiety Inventory. This consisted of twenty statements, and the task for the patient was to best indicate how he or she felt at the time of the assessment. At preoperative neuropsychologic examination verbal and nonverbal intelligence quotient assessment was undertaken using the vocabulary test and the picture completion test from the Weschler Adult Intelligence Scale Manual. $^{50}$ 